\title{
Evaluation of the Palatability of Dry Syrups and the Bitterness Intensities of Dry Syrups Mixed with Various Beverages
}

\author{
Toshio Kurihara, Honami Kojima, Miyako Yoshida, Mizuho Oshio, Rino Kunikata, \\ Haruka Nishikawa, Takahiro Uchida
}

Faculty of Pharmaceutical Sciences, Mukogawa Women's University, Nishinomiya, Japan

Email: takahiro@mukogawa-u.ac.jp

How to cite this paper: Kurihara, T., Kojima, H., Yoshida, M., Oshio, M., Kunikata, R., Nishikawa, H. and Uchida, T. (2021) Evaluation of the Palatability of Dry Syrups and the Bitterness Intensities of Dry Syrups Mixed with Various Beverages. Pharmacology \& Pharmacy, 12, 43-54.

https://doi.org/10.4236/pp.2021.122004

Received: January 21, 2021

Accepted: February 23, 2021

Published: February 26, 2021

Copyright $\odot 2021$ by author(s) and Scientific Research Publishing Inc. This work is licensed under the Creative Commons Attribution International License (CC BY 4.0).

http://creativecommons.org/licenses/by/4.0/

\begin{abstract}
The purpose of this study was to evaluate the palatability of dry syrups for pediatric use by human gustatory sensation testing and the artificial taste sensor. The bitterness intensities of dry syrups mixed with various beverages were also evaluated using the taste sensor. Twenty dry-syrup formulations of antibacterial and anti-allergic drugs containing bitter active ingredients, frequently used in pediatric medicine in Japan, were selected for testing. The main factors influencing palatability were determined by factor analysis of data from human gustatory sensation testing using the semantic differential method. It was shown that the bitterness intensity of dry syrups in water could be predicted by the artificial taste sensor. The influence of different beverages (orange juice, milk or cocoa) mixed with the dry syrups was evaluated using the artificial taste sensor. Taste and texture were found to be the principal factors influencing the palatability of dry syrups. While the bitterness intensities of some dry syrups were increased by mixing with orange juice, the bitterness intensities of most dry syrups were decreased by mixing with milk or cocoa. This suggests that one or more constituents of milk or cocoa may reduce the bitterness intensities of dry syrups.
\end{abstract}

\section{Keywords}

Palatability, Semantic Differential Method, Dry Syrup, Taste Sensor

\section{Introduction}

Dry syrups are oral pharmaceutical formulations particularly suited for use in pediatric medicine. As with other oral pharmaceutical formulations, the palatability of a dry syrup can have a profound impact on therapeutic outcome. If the 
bitterness of an active pharmaceutical ingredient causes poor palatability, drug efficacy may be reduced due to non-compliance [1]. The exploration of factors influencing the palatability of dry syrups may therefore lead to improvements in their pharmaceutical formulation.

The semantic differential (SD) method developed by Osgood et al. [2] is a method used to quantify an image. In a previous study, we have used the SD method in human taste testing studies to evaluate the palatability of total enteral nutrients [3]. In the present study, the SD method was used to explore the factors influencing the palatability of 20 dry syrups currently marketed in Japan and commonly used in pediatric medicine.

The use of the artificial taste sensor for pharmaceutical purposes is an innovation which has reduced dependence on human gustatory sensation testing. The bitterness of active pharmaceutical ingredients in oral pharmaceutical formulations has previously been evaluated using the artificial taste sensor or "electronic tongue" [4]-[10]. There are several types of sensors which have different components of lipids and plasticizers and are sensitive to different materials: $\mathrm{C} 00$ is sensitive to acidic bitter materials such as diclofenac sodium, a non-steroidal anti-inflammatory drug [4]; AE1 is sensitive to astringent materials such as tannic acid; ACO and AN0 are sensitive to basic materials such as solifenacin succinate [6] or amlodipine besilate [7] and BT0 is sensitive to hydrochloride salts, including quinine hydrochloride [9]. The bitterness of an active pharmaceutical ingredient in oral pharmaceutical formulations mixed with various foods or beverages has also been evaluated using a taste sensor [11] [12].

The purpose of this study was to identify the main factors influencing the palatability of 20 dry syrups marketed in Japan. The novelty of this study is that the palatability of these dry syrups, which are often taken by children, was evaluated by a combination of two methods, human gustatory sensation testing using the SD method and evaluation by the artificial taste sensor. Factor analysis was performed on quantified images of the dry syrups obtained using the SD method and the two main factors influencing palatability were extracted. To evaluate the influence of mixing the dry syrups with different beverages on their bitterness, the bitterness intensities of dry syrups mixed with orange juice, milk or cocoa were measured using the taste sensor.

\section{Material and Methods}

\subsection{Materials}

Unasyn $^{\oplus}$ fine granules for pediatric use 10\% (Pfizer Japan Inc.), Clavamox combination dry syrup for pediatric (GlaxoSmithKline K.K.), Larixin ${ }^{\circledR}$ dry syrup for pediatric (FUJIFILM Toyama Chemical Co., Ltd.), Oraspor ${ }^{\circledR}$ dry syrup $10 \%$ for pediatric (Alfresa Pharma Corp.), Kefral ${ }^{\circ}$ fine granules for pediatric (Kyowa Pharmaceutical Industry Co., Ltd.), Tomiron ${ }^{\circledR}$ dry syrup for pediatric (FUJFILM Toyama Chemical Co., Ltd.), Cefzon ${ }^{\otimes}$ fine granules $10 \%$ for pediatric (LTL Pharma Co., Ltd.), Banan ${ }^{\bowtie}$ dry syrup 5\% (GlaxoSmithKline K.K.), Meiact MS ${ }^{\circledast}$ 
fine granules 10\% (Meiji Seika Pharma Co., Ltd.), Flomox ${ }^{\oplus}$ fine granules for pediatric (Shionogi \& Co., Ltd.), Orapenem ${ }^{\bullet}$ fine granules $10 \%$ for pediatric (Meiji Seika Pharma Co., Ltd.), Farom ${ }^{\circledR}$ dry syrup 10\% for pediatric (Maruho Co., Ltd.), Clarith $^{\otimes}$ dry syrup $10 \%$ for pediatric (Taisho Pharmaceutical Co., Ltd.), Rizaben ${ }^{\circledR}$ dry syrup 5\% (Kissei Pharmaceutical Co., Ltd.), Zaditen ${ }^{\circledR}$ dry syrup 0.1\% (SUN Pharma Japan Ltd.), Allegra ${ }^{\oplus} 5 \%$ dry syrup (Sanofi K.K.), Alesion ${ }^{\circledR}$ dry syrup $1 \%$ (Boehringer Ingelheim Japan, Inc.), Zyrtec ${ }^{\oplus}$ dry syrup 1.25\% (Daiichi Sankyo Co., Ltd.), Claritin ${ }^{\circledR}$ dry syrup 1\% (Shionogi \& Co., Ltd.), Onon ${ }^{\circledR}$ dry syrup 10\% (Ono Pharmaceutical Co., Ltd.), Orange juice (Tropicana 100\% marugoto-kajitsukan orange, Kirin Beverage Co., Ltd.), Milk (Meiji oishii-gyunyu, Meiji Co., Ltd.), Cocoa (Kissaten-no-aji cocoa, Moriyama Co., Ltd.).

\subsection{Human Gustatory Sensation Testing}

Samples of dry syrups containing a single dose for a 3 - 4-year-old (bodyweight $14 \mathrm{~kg}$ ) were used for human gustatory sensation testing using 10 well-trained volunteers (mean age $32 \pm 13.5$ years). The dry syrups were mixed with $10 \mathrm{~mL}$ water for $5 \mathrm{~s}$ and all samples were kept in the mouth for $5 \mathrm{~s}$. In a previous study, the palatability scores of various total enteral nutrients have been evaluated using the SD method [13]. As in the previous study, the volunteers were asked to score the samples on the basis of 11 items, each expressed in symmetrical terms representing the extremities for each item, as follows: 1) Bad smell/Good smell, 2) Bad feeling on the tongue/Good feeling on the tongue, 3) Powdery/Not powdery, 4) Feeling of roughness on the tongue/No feeling of roughness on the tongue, 5) Weak sweetness/Strong sweetness, 6) Weak sourness/Strong sourness, 7) Weak bitterness/Strong bitterness, 8) Bad taste/Good taste, 9) Bad after-taste/ Good after-taste, 10) No sensation of coolness/Sensation of coolness, 11) Bad overall impression/Good overall impression. The items were each scored on the following rating scale: extremely 1 , slightly 2 , neither 3 , slightly 4 , or extremely 5 .

None of the volunteers reported having a cold or other respiratory tract infection in the week prior to testing. They were asked to refrain from eating, drinking, or chewing gum for at least 1 hour prior to testing. All volunteers were non-smokers and signed an informed consent form before the experiments. The experimental protocol of this study (No. 20-54) was approved in advance, on Oct 17, 2020, by the ethical committee of Mukogawa Women's University.

\subsection{Dispersibility of Dry Syrups in Water}

The samples were prepared by mixing a single dose of dry syrup with $10 \mathrm{~mL}$ water. Photographs were taken of all samples after mixing with water for $5 \mathrm{~s}$.

\subsection{Taste Sensor Measurements of Dry Syrups Mixed with Beverages}

Taste sensor SA402B (Intelligent Sensor Technology Inc., Atsugi, Japan) was used to measure the electric potential of the sample solutions (at the same con- 
centrations as those used in human gustatory sensation testing) in order to predict their taste. Sensor AC0, developed specifically to detect the bitterness of basic substances [14] [15] [16], was used in these experiments. The taste sensor measurements were performed to evaluate bitterness intensity for amlodipine besilate [6], solifenacin succinate [7], $\mathrm{H}_{1}$-receptor antagonists [9] and topiramate [17] as described in previous articles.

The measurement procedure is as follows: the electrodes are dipped into the reference solution and the electric potential obtained $(\mathrm{mV})$ is defined as $\mathrm{Vr}_{0}$. Then the electric potential of a sample solution is measured and defined as Vs. The relative sensor output $(\mathrm{R})$, represented by the difference between the potentials of the sample and the reference solution $\left(\mathrm{Vs}^{-}-\mathrm{Vr}_{0}\right)$, corresponds to the "taste immediately after putting in the mouth". The electrodes are then rinsed with fresh reference solution for $6 \mathrm{~s}$. When the electrodes are dipped into the reference solution again, the new potential of the reference solution is defined as $\mathrm{Vr}_{1}$. The difference between the potentials of the reference solution before and after sample measurement $\left(\mathrm{Vr}_{1}-\mathrm{Vr}_{0}\right)$ is defined as the "Change in the membrane Potential caused by Adsorption" (CPA), and corresponds to the so-called "aftertaste". CPA is used as the index of bitterness intensity of dry syrups.

In these experiments we first measured the predicted bitterness intensity of the dry syrups in water. Secondly, we measured the predicted bitterness intensity of dry syrups mixed with each of the three beverages (orange juice, milk and cocoa).

\section{5. pH Measurement of Dry Syrup Mixed with Beverages}

In order to examine the influence of the beverages on the $\mathrm{pH}$ of the samples, the $\mathrm{pH}$ of all samples was determined in a $\mathrm{pH}$ meter (Horiba Ltd., Kyoto, Japan). All samples were prepared in the same manner as those for the taste sensor measurements.

\subsection{Statistical Analysis}

BellCurve for Excel $^{\Phi}$ (Social Survey Research Information Co., Ltd., Japan) was used for statistical analysis. The data obtained by the SD method were analyzed by factor analysis (a factor axis was rotated using a varimax method) and multiple regression analysis. Tukey's test was used for multiple comparisons. Correlations were examined using Pearson's product-moment correlation coefficient. The $5 \%$ level of probability was considered significant.

\section{Results and Discussion}

\subsection{The Palatability of Dry Syrups in Human Gustatory Sensation Testing Using the SD Method}

Figure 1 shows the palatability scores obtained from human gustatory sensation testing using the SD method. A factor analysis (rotated using a varimax method) was performed on these palatability scores. Table 1 shows the factor loading of 
the extracted items. For the first factor, the factor loading (absolute value) of four items was close to 1 . The four items and their factor loadings were as follows: bitterness 0.9578 , aftertaste 0.9249 , taste 0.9010 and overall impression 0.8616. The first factor was thereby defined as taste. For the second factor, the factor loading of three items was close to 1 . The three items and their factor loadings were as follows: powdery 0.9033 , feeling of roughness on the tongue 0.9029 , and feeling on the tongue 0.8876 . The second factor was thereby defined as texture. The results of the factor analysis therefore suggest that the palatability of dry syrups is principally influenced by taste and texture.

Table 1. Factor loadings obtained from human gustatory sensation testing using the SD method.

\begin{tabular}{|c|c|c|c|}
\hline \multirow{2}{*}{ Factor } & \multirow{2}{*}{ Items } & \multicolumn{2}{|c|}{ The factor loading } \\
\hline & & First factor & Second factor \\
\hline \multirow{4}{*}{ Taste } & Bitterness & -0.9578 & 0.0472 \\
\hline & After-taste & 0.9249 & -0.0238 \\
\hline & Taste & 0.9010 & -0.0644 \\
\hline & Overall impression & 0.8616 & 0.3258 \\
\hline \multirow{3}{*}{ Texture } & Powdery & 0.0135 & 0.9033 \\
\hline & Feeling roughness on the tongue & -0.0174 & 0.9029 \\
\hline & Feeling on the tongue & -0.0825 & 0.8876 \\
\hline
\end{tabular}

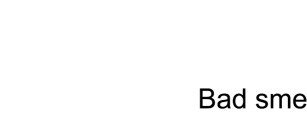

Bad feeling on the tongue

Powdery

Feeling roughness on the tongue

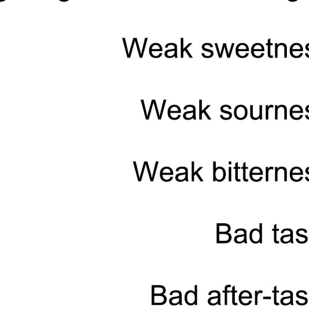

Not sensation of coolness

Bad overall impression

5

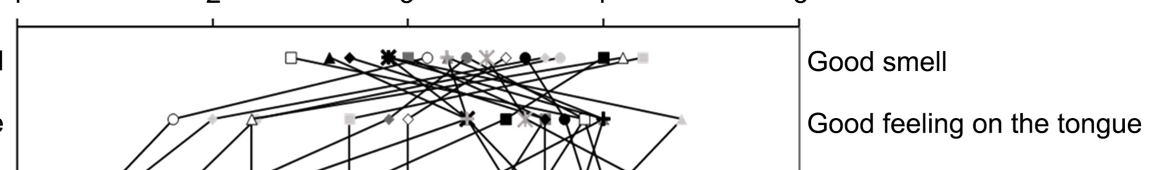

Not powdery

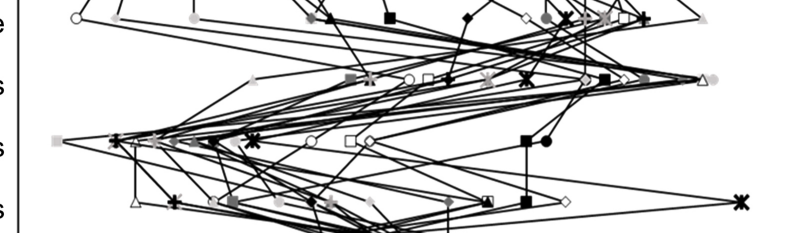

Not feeling roughness on the tongue

Strong sweetness

Strong sourness

Strong bitterness

Good taste

Good after-taste

Sensation of coolness

Good overall impression

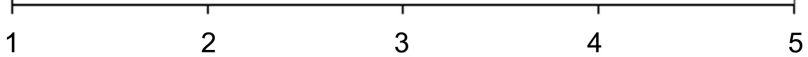

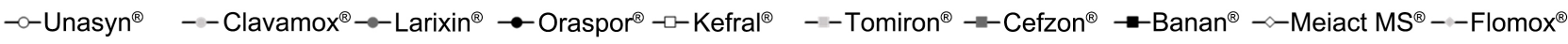

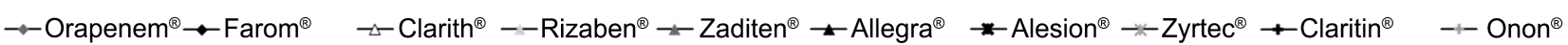

Figure 1. Palatability scores obtained from human gustatory sensation testing using the SD method $(\mathrm{n}=10)$. 
Figure 2 shows the scatter plot of the two factor scores for each dry syrup. The X-axis reflects the factor score of the first factor "taste", and the Y-axis reflects the factor score of the second factor "texture". The contribution rates of the first and second factors were $35.77 \%$ and $31.28 \%$, respectively. The higher the score of the first factor, the better the taste of the dry syrup and the higher the score of the second factor, the better the feeling when the dry syrup is put in the mouth. These results suggest that the palatability of Zyrtec ${ }^{\circledast}$, Cefzon ${ }^{\circledast}$, Claritin $^{\circledast}$, Rizaben ${ }^{\circledast}$, Onon $^{\circledast}$, Oraspor ${ }^{\circledast}$, Larixin ${ }^{\circledast}$ and Zaditen ${ }^{\circledast}$ is good while that of Flomox $^{\circledast}$, Orapenem ${ }^{\circledast}$, Allegra ${ }^{\circledast}$ and Meiact $\mathrm{MS}^{\circledast}$ is poor. It has previously been reported that a feeling of roughness of powders and granules on the tongue is a reason given for difficulty in taking medicines in children [17]. Therefore, it is reasonable to extract texture as a major factor influencing the palatability of dry syrups.

\subsection{The Dispersibility of Dry Syrups in Water}

Figure 3 shows the dispersibility of the dry syrups mixed with water for $5 \mathrm{~s}$. Nine of the dry syrups (Unasyn ${ }^{\oplus}$, Clavamox ${ }^{\circledast}$, Tomiron $^{\circledast}$, Banan $^{\oplus}$, Meiact MS $^{\circledast}$, Flomox $^{\circledast}$, Orapenem ${ }^{\circledast}$, Clarith ${ }^{\circledast}$ and Allegra ${ }^{\circledR}$ ) remained powdery. These nine dry syrups also had low scores for "powdery" in human gustatory sensation testing, as seen in Figure 1. In other words, the dispersibility of the nine dry syrups as seen in the photographs corresponds with the score for "powdery" obtained in human gustatory sensation testing.

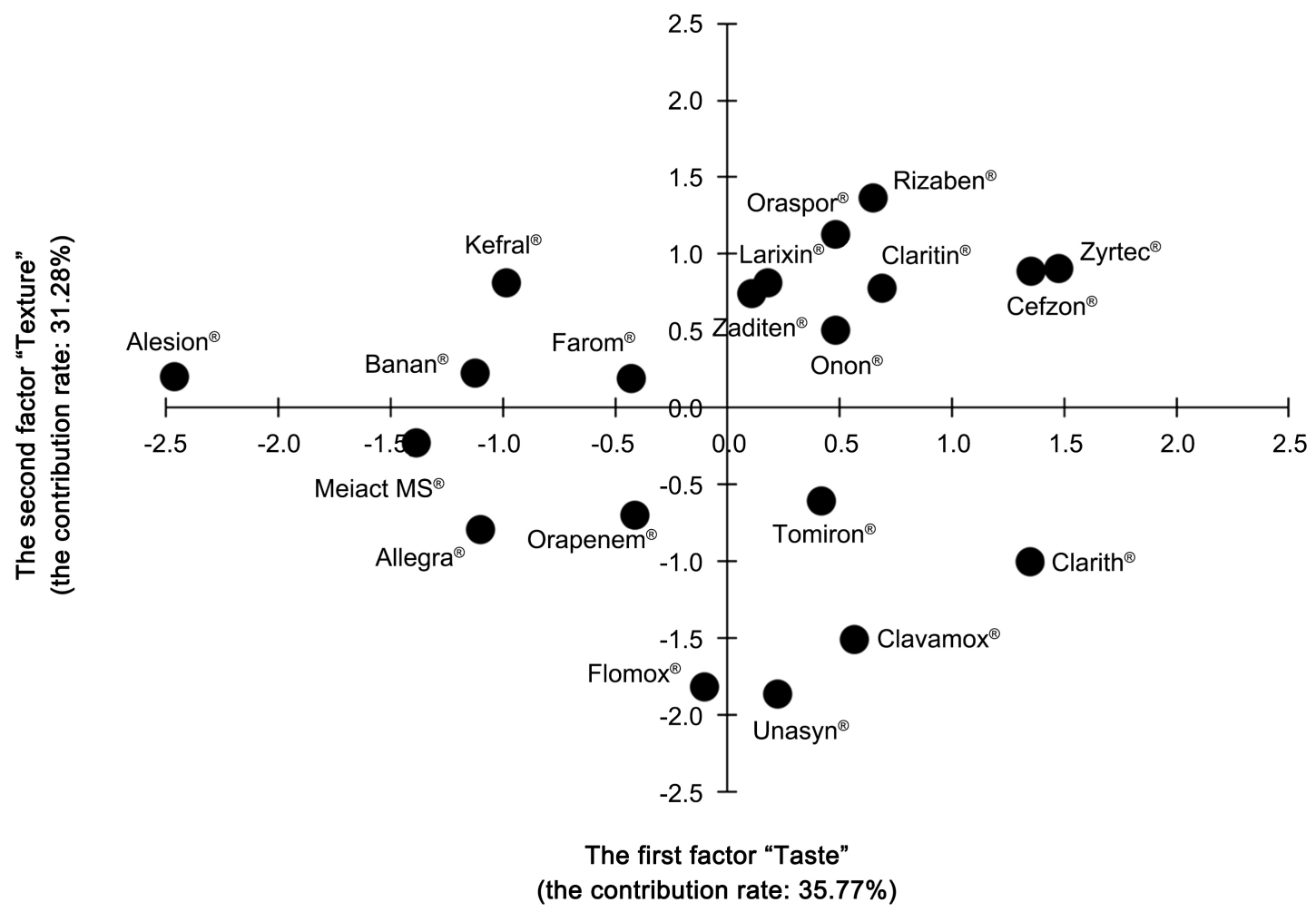

Figure 2. Scatter plot of factor scores for each dry syrup. 


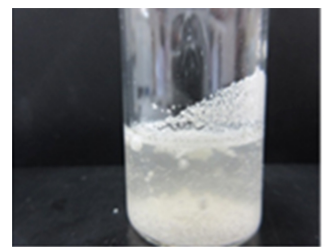

Unasyn $^{\circledR}$ fine granules for pediatric use $10 \%$

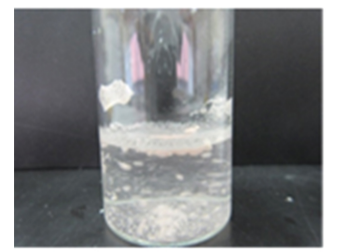

Tomiron ${ }^{\circledR}$ dry syrup for pediatric

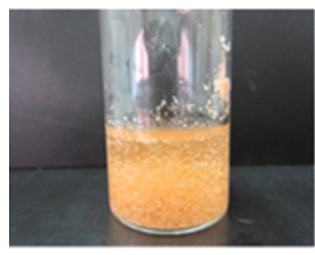

Orapenem ${ }^{\circledR}$ fine granules $10 \%$ for pediatric

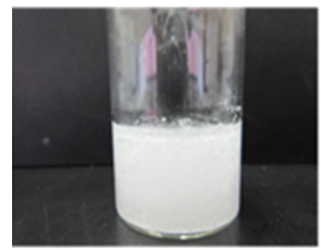

Allegra $^{\circledR} 5 \%$ dry syrup

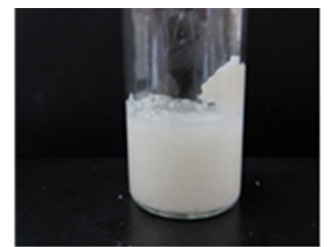

Clavamox combination dry syrup for pediatric

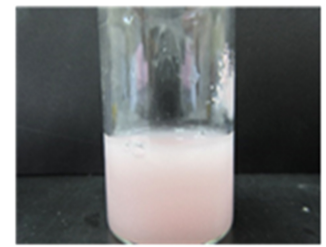

Cefzon ${ }^{\circledR}$ fine granules $10 \%$ for pediatric

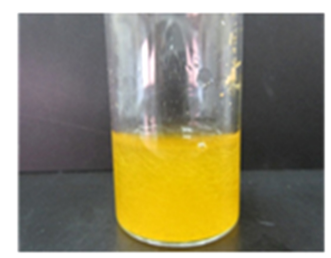

Farom $^{\circledR}$ dry syrup for pediatric

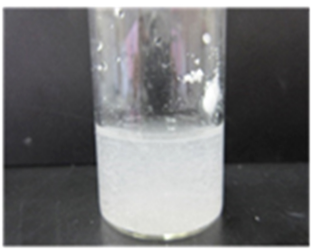

Alesion ${ }^{\circledR}$ dry syrup $1 \%$

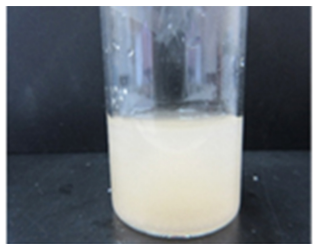

Larixin $^{\circledast}$ dry syrup for pediatric

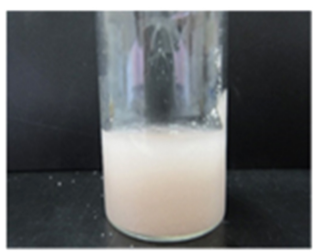

Banan $^{\circledR}$ dry syrup $5 \%$

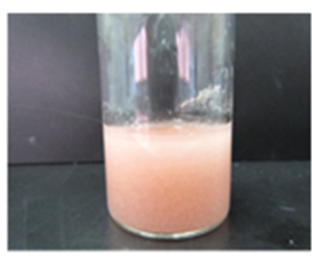

Clarith $^{\circledR}$ dry syrup $10 \%$ for pediatric

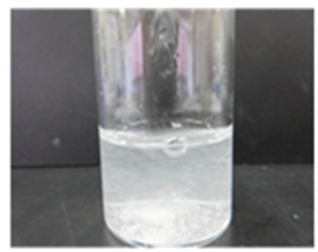

Zyrtec $^{\circledR}$ dry syrup $1.25 \%$

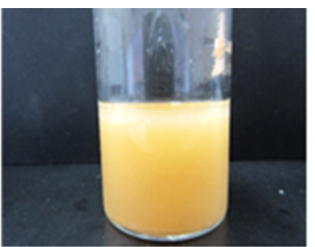

Oraspor $^{\circledR}$ dry syrup $10 \%$ for pediatric

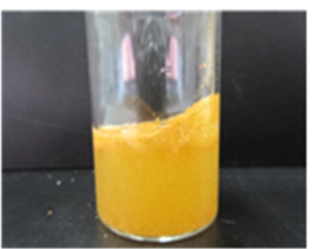

Meiact $\mathrm{MS}^{\circledR}$ fine granules $10 \%$

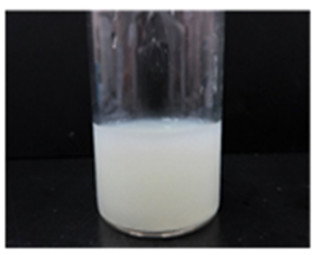

Rizaben $^{\circledR}$ dry syrup $5 \%$

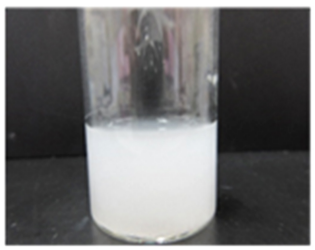

Claritin $®$ dry syrup $1 \%$

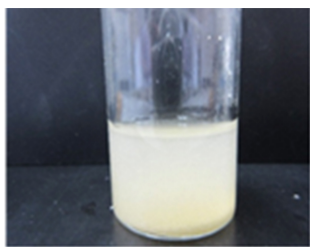

Kefral ${ }^{\circledR}$ fine granules for pediatric

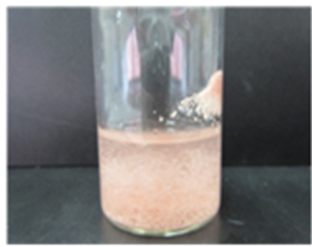

Flomox $^{\circledR}$ fine granules for pediatric

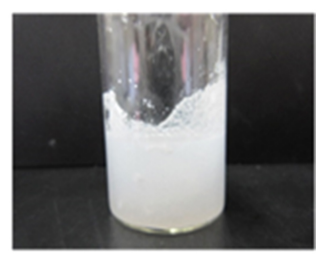

Zaditen $^{\circledR}$ dry syrup $0.1 \%$

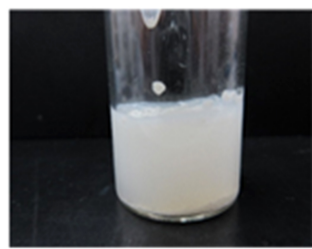

Onon ${ }^{\circledR}$ dry syrup $10 \%$

Figure 3 . The dispersibility of dry syrups in water.

\subsection{The Bitterness Intensity of Dry Syrups: Taste Sensor Measurements and Human Taste Tests}

Figure 4 shows the bitterness intensities of dry syrups in water obtained from taste sensor measurements and human gustatory sensation testing. Alesion ${ }^{\oplus}$, Meiact $\mathrm{MS}^{\circledast}, \mathrm{Banan}^{\circledR}$ and Allegra ${ }^{\circledR}$ demonstrated high bitterness using both methods. There was a significant correlation between the bitterness intensities obtained from human gustatory sensation testing and sensor outputs from taste sensor measurements for dry syrups in water $(r=0.655$, Pearson's product-moment correlation coefficient, $\mathrm{p}=0.0017$ ). This result shows that the bitterness of dry syrups in water could be accurately predicted by the taste sensor. 


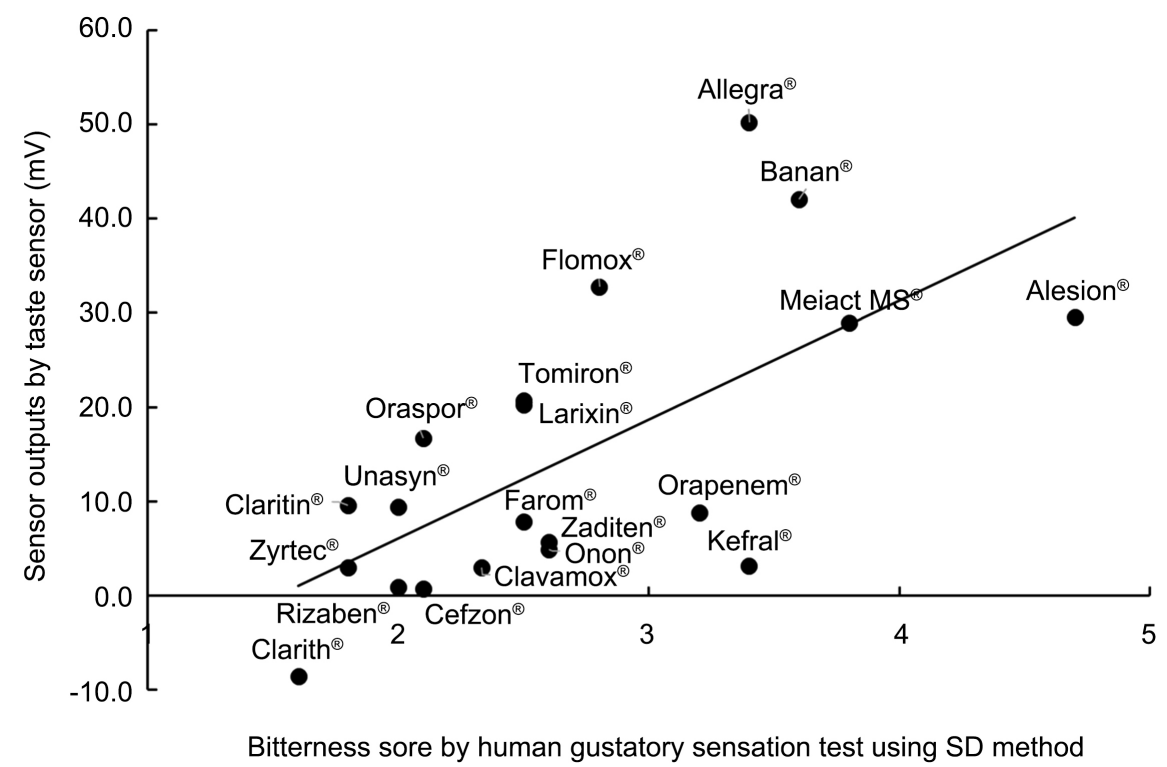

Figure 4. The correlation between bitterness intensities of dry syrups in water as measured by the taste sensor and in human gustatory sensation tests. $r=0.655$ ( $p=0.0017$, Pearson's product-moment correlation coefficient).

\subsection{The pH of Dry Syrups Mixed with Beverages}

Figure 5(a) shows the $\mathrm{pH}$ of dry syrups mixed with water or orange juice. The $\mathrm{pH}$ of only orange juice was 4.0 and this is acidic beverage. In most cases, the $\mathrm{pH}$ of dry syrups mixed with orange juice was lower than that of mixtures with water. The $\mathrm{pH}$ of all samples was around $\mathrm{pH}$ 4.0. Figure 5(b) and Figure 5(c) show the $\mathrm{pH}$ of dry syrups mixed with milk and water, or cocoa and water, respectively. The $\mathrm{pH}$ of only milk and cocoa were 6.8 and 6.9 , respectively. Those are neutral beverages. In most cases, the $\mathrm{pH}$ of the dry syrups mixed with milk or cocoa was higher than that of dry syrups mixed with water. The $\mathrm{pH}$ of most dry syrups mixed with milk or cocoa was in the range $6-7$. These results show that mixing with beverages alters the $\mathrm{pH}$ of dry syrups.

\subsection{The Influence of Beverages on Bitterness Intensity of Dry Syrups: Taste Sensor Measurements}

Figure 6(a) shows the bitterness intensities of dry syrups mixed with water or orange juice as measured by the taste sensor. The sensor outputs for Unasyn ${ }^{\oplus}$, Flomox $^{\oplus}$ and Clarith ${ }^{\oplus}$ mixed with orange juice were higher than when they were mixed with water. On the drug package insert of Unasin ${ }^{\circledast}$ it states that the product is coated to disguise the bitterness of the active pharmaceutical ingredient, so it should be taken immediately with water or milk, avoiding acidic beverages, without crushing or dissolving the granules [18]. The drug package inserts of Flomox $^{\oplus}$ and Clarith ${ }^{\circledR}$ contain similar warnings [19] [20]. These messages all indicate that the bitterness of Unasyn ${ }^{\oplus}$, Flomox ${ }^{\circledR}$ and Clarith $^{\circledR}$ may be increased by breaking the coating of the dry syrup on mixing with an acidic beverage such as orange juice. 
(a)

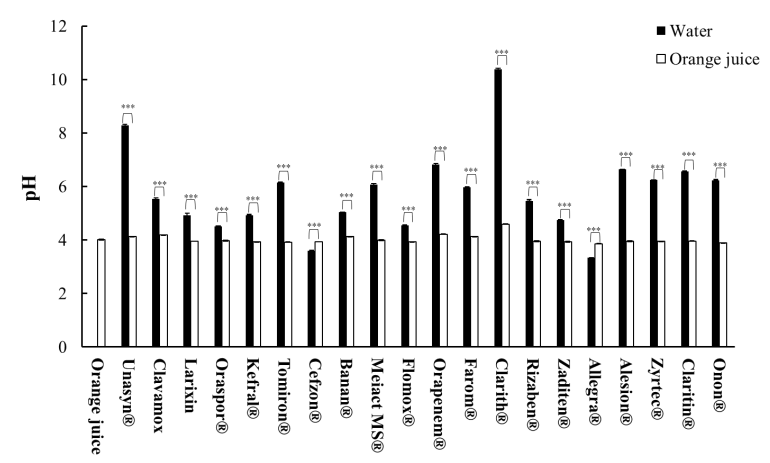

(c)

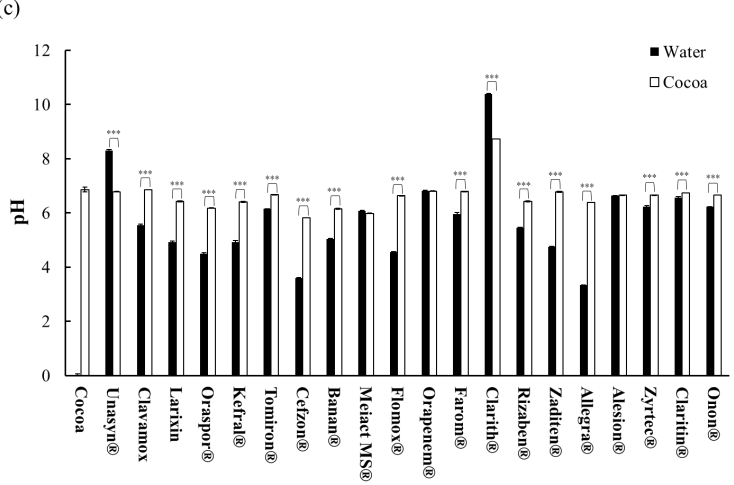

(b)

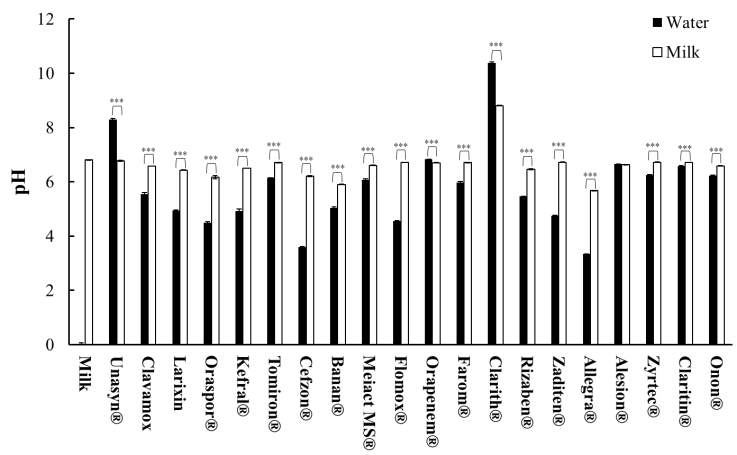

Figure 5. pH of dry syrup mixed with (a) water and orange juice, (b) water and milk, and (c) water and cocoa. $n=6$, mean \pm S.D. ${ }^{* * *} \mathrm{p}<0.001$ versus orange juice or milk or cocoa (Tukey's test).

(a)

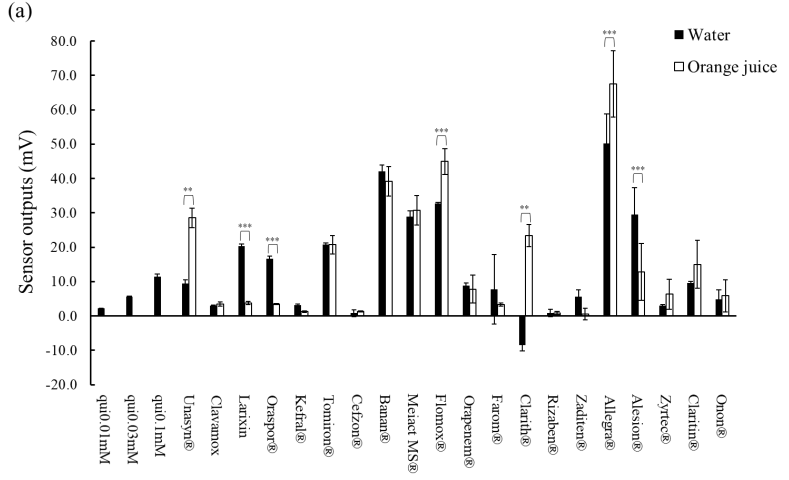

(c)

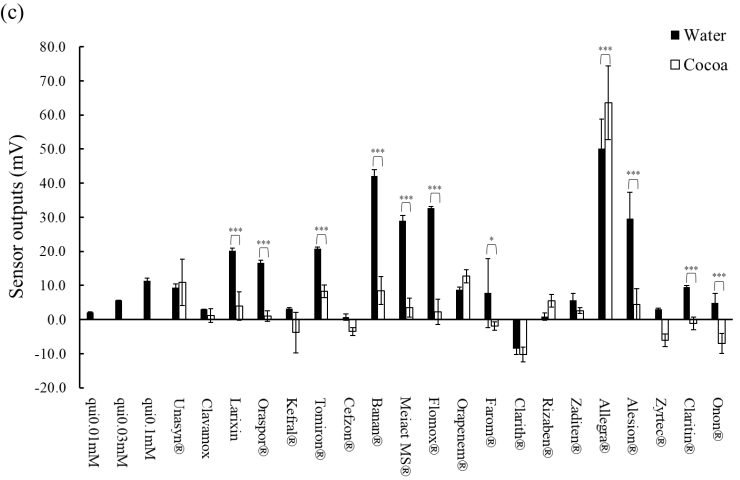

(b)

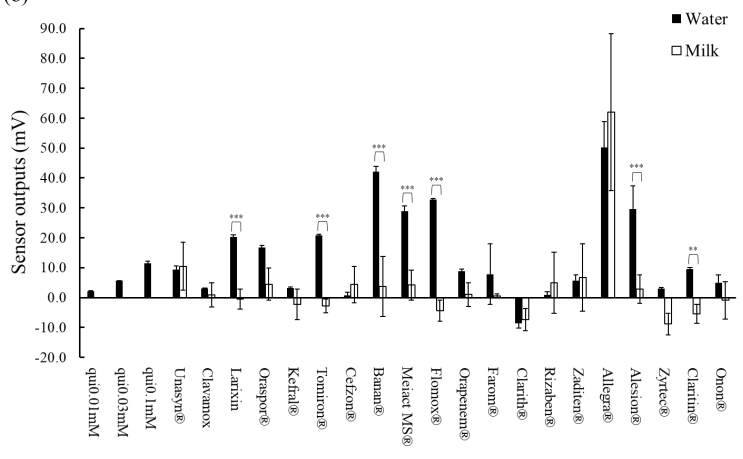

Figure 6. The influence of beverages on the bitterness intensity of dry syrups as measured by the taste sensor; (a) orange juice, (b) milk, (c) cocoa. $\mathrm{n}=6$, mean \pm S.D. ${ }^{\star} \mathrm{p}<0.05,{ }^{* *} \mathrm{p}<0.01,{ }^{* * *} \mathrm{p}<0.001$ versus orange juice, milk or cocoa, respectively (Tukey’s test). 
Figure 6(b) shows the bitterness intensities of dry syrups mixed with water or milk. The sensor outputs of most dry syrups mixed with milk were lower than when they were mixed with water. It has been reported that $\beta$-lactoglobulin, contained in the lipoproteins in milk, binds to the microvillous membranes of taste cells and thus prevents bitter substances binding to receptors [21] [22]. It is suggested that this mechanism underlies the observation that the bitterness of dry syrups is decreased by mixing with milk. Figure 6(c) shows the bitterness intensities of dry syrups mixed with water or cocoa. The sensor outputs of most dry syrups mixed with cocoa were lower than when they were mixed with water. It has been reported that phosphatidic acid, contained in the soybean oil in cocoa, suppresses bitterness [21] [22]. This may be the reason that the bitterness of most dry syrups was decreased by mixing with cocoa. It is hypothesized that the reason that milk suppresses the bitterness of these dry syrups more than cocoa is that milk contains more fat than cocoa. These results show that the bitterness intensities of dry syrups can be decreased by mixing with milk or cocoa, thus improving their palatability.

Multiple regression analysis was performed to investigate correlations between three tastes: "sweetness", "sourness" and "bitterness" (explanatory variables) and the "taste" of dry syrups (target variable) in order to obtain partial regression coefficients. A multiple regression formula for the "taste" of dry syrups was obtained $(\mathrm{R}=0.9312, \mathrm{p}<0.001)$, as described below.

Predicted "taste" of dry syrup

$=0.2868 \times$ “sweetness" $-0.8673 \times$ “bitterness" +4.1973

"Sweetness" and "bitterness" were found to have significant regression coefficients with the "taste" of dry syrups ("sweetness" $\mathrm{p}=0.0042$, "bitterness" $\mathrm{p}<$ 0.001). "Sourness" was not found to have significant regression coefficients. Therefore, we conclude that, of the three tastes tested, "sweetness" and "bitterness" showed the best correlations with the overall "taste" of dry syrups. However, it has also been described in a previous article that excessive sweetness can be a reason for difficulty in taking medicines in children [20]. As the partial correlation coefficient of bitterness was larger than that of sweetness in multiple regression analysis, this suggests that the masking of bitterness is more important than the addition of sweetness when attempting to improve the palatability of dry syrups

\section{Conclusions}

The palatability of dry syrups can have a profound impact on therapeutic outcomes when the bitterness of an active pharmaceutical ingredient reduces drug efficacy through non-compliance. Investigation of factors influencing the palatability of dry syrups which may lead to improvements in drug formulation may therefore also improve clinical outcomes. In human gustatory sensation testing using the SD method, it was shown that taste and texture were the main factors influencing the palatability of dry syrups. When these factors were evaluated in 
the taste sensor, it was shown that the bitterness intensities of some dry syrups were actually increased by mixing with orange juice while in most cases bitterness was decreased by mixing with milk or cocoa.

In conclusion, these results suggest that taking dry syrups with milk or cocoa may improve their palatability by reducing their bitterness.

\section{Acknowledgements}

This work was supported by a Grant-in-Aid for Scientific Research (C) from the Japan Society for Promotion of Science 16K08425 (to Miyako Uchida).

\section{Conflicts of Interest}

The authors declare no conflicts of interest regarding the publication of this paper.

\section{References}

[1] Mennella, J.A., Spector, A.C., Reed, D.R. and Coldwell, S.E. (2013) The Bad Taste of Medicines: Overview of Basic Research on Bitter Taste. Clinical Therapeutics, 35, 1225-1246. https://doi.org/10.1016/j.clinthera.2013.06.007

[2] Osgood, E.C., Suci, G.J. and Tannenbaum, P.H. (1957) The Measurement of Meaning. University of Illinois Press, Urbana.

[3] Mukai, J., Miyanaga, Y., Ishizaka, T., Akasa, K., Nakai, Y., Tsuji, E. and Uchida, T. (2004) Quantitative Taste Evaluation of Total Enteral Nutritions. Chemical and Pharmaceutical Bulletin, 52, 1416-1421. https://doi.org/10.1248/cpb.52.1416

[4] Yoshida, M., Haraguchi, T. and Uchida, T. (2014) Bitterness Evaluation of Acidic Pharmaceutical Substances (NSAIDs) Using a Taste Sensor. Chemical and Pharmaceutical Bulletin, 62, 1252-1258. https://doi.org/10.1248/cpb.c14-00577

[5] Kobayashi, Y., Habara, M., Ikezazki, H., Chen, R., Naito, Y. and Toko, K. (2010) Advanced Taste Sensors Based on Artificial Lipids with Global Selectivity to Basic Taste Qualities and High Correlation to Sensory Scores. Sensors, 10, 3411-3443. https://doi.org/10.3390/s100403411

[6] Uchida, T., Yoshida, M., Hazekawa, M., Haraguchi, T., Fruno, H., Teraoka, M. and Ikezaki, H. (2013) Evaluation of Palatability of 10 Commercial Amlodipine Orally Disintegrating Tablets by Gustatory Sensation Testing, OD-Mate as a New Disintegration Apparatus and the Artificial Taste Sensor. The Journal of Pharmacy and Pharmacology, 65, 1312-1320. https://doi.org/10.1111/jphp.12101

[7] Haraguchi, T., Miyazaki, A., Yoshida, M. and Uchida, T. (2013) Bitterness Evaluation of Intact and Crushed Vesicare Orally Disintegrating Tablets Using Taste Sensors. The Journal of Pharmacy and Pharmacology, 65, 980-987. https://doi.org/10.1111/jphp.12078

[8] Wu, X., Onitake, H., Haraguchi, T., Tahara, Y., Yatabe, R., Yoshida, M., Uchida, T., Ikezaki, H. and Toko, K. (2016) Quantitative Prediction of Bitterness Masking Effect of High-Potency Sweeteners Using Taste Sensor. Sensors and Actuators B: Chemical, 235, 11-17. https://doi.org/10.1016/j.snb.2016.05.009

[9] Ito, M., Yoshida, M., Kobayashi, Y., Hiraoka, M., Ikezaki, H. and Uchida, T. (2011) Bitterness Evaluation of H1-Receptor Antagonists Using a Taste Sensor. Sensors and Materials, 23, 483-492. https://doi.org/10.18494/SAM.2011.771 
[10] Yoshimatsu, J., Toko, K., Tahara, Y., Ishida, M., Habara, M., Ikezaki, H., Kojima, H., Ikegami, S., Yoshida, M. and Uchida, T. (2020) Development of Taste Sensor to Detect Non-Charged Bitter Substances. Sensors, 20, 3455. https://doi.org/10.3390/s20123455

[11] Haraguchi, T., Uchida, T., Hazekawa, M., Yoshida, M., Nakashima, M., Sanda, H., Hase, T. and Tomoda, Y. (2016) Ability of Food/Drink to Reduce the Bitterness Intensity of Topiramate as Determined by Taste Sensor Analysis. Chemical and Pharmaceutical Bulletin, 64, 14-20. https://doi.org/10.1248/cpb.c15-00474

[12] Yoshida, M., Kojima, H., Uda, A., Haraguchi, T., Ozeki, M., Kawasaki, I., Yamamoto, K., Yano, I., Hirai, M. and Uchida, T. (2019) Bitterness-Masking Effects of Different Beverages on Zopiclone and Eszopiclone Tablets, Chemical and Pharmaceutical Bulletin, 67, 404-409. https://doi.org/10.1248/cpb.c18-00502

[13] Mukai, J., Ishizaka, T., Asaka, K., Tokuyama, E., Tsuji, E. and Uchida, T. (2006) Quantitative Evaluation of Total Enteral Nutrient Palatability. Journal of Pharmaceutical Health Care and Sciences, 32, 13-20. https://doi.org/10.5649/jiphcs.32.13

[14] Kobayashi, Y., Habara, M., Ikezazki, H., Chen, R., Naito, Y. and Toko, K. (2010) Advanced Taste Sensors Based on Artificial Lipids with Global Selectivity to Basic Taste Qualities and High Correlation to Sensory Scores. Sensors, 10, 3411-3443. https://doi.org/10.3390/s100403411

[15] Haraguchi, T., Uchida, T., Yoshida, M., Kojima, H., Habara, M. and Ikezaki, H. (2018) The Utility of the Artificial Taste Sensor in Evaluating the Bitterness of Drugs: Correlation with Responses of Human TASTE2 Receptors (hTAS2Rs). Chemical and Pharmaceutical Bulletin, 66, 71-77. https://doi.org/10.1248/cpb.c17-00619

[16] Haraguchi, T., Okuno, T., Nishikawa, H., Kojima, H., Ikegami, S., Yoshida, M., Habara, M., Ikezaki, H. and Uchida, T. (2019) The Relationship between Bitter Taste Sensor Response and Physicochemical Properties of 47 Pediatric Medicines and Their Biopharmaceutics Classification. Chemical and Pharmaceutical Bulletin, 67, 1271-1277. https://doi.org/10.1248/cpb.c19-00508

[17] Shimokawa, K., Itabashi, T., Yamazaki, N., Hino, F. and Ishii, F. (2009) Survey of Administration Methods with View to Improving Compliance in Pediatric Patients. Journal of Pharmaceutical Health Care and Sciences, 35, 662-668. https://doi.org/10.5649/jiphcs.35.662

[18] Pfizer Japan Inc. (2019) Drug Package Insert "Unasyn Fine Granules for Pediatric Use $10 \% "$.

[19] Shionogi \& Co., Ltd. (2020) Drug Package Insert "Flomox Fine Granules for Pediatric Use".

[20] Taisho Pharmaceutical Co., Ltd. (2020) Drug Package Insert "Clarith Dry Syrup $10 \%$ for Pediatric Use".

[21] Katsuragi, Y., Sugiura, Y., Lee, C., Otsuji, K. and Kurihara, K. (1995) Selective Inhibition of Bitter Taste of Various Drugs by Lipoprotein. Pharmaceutical Research, 12, 658-662. https://doi.org/10.1023/A:1016295122461

[22] Katsuragi, Y., Sugiura, Y., Otsuji, K. and Kurihara, K. (1996) Characteristics of Phosphatidic Acid-Containing Lipoproteins Which Selectively Inhibit Bitter Taste: High Affinity to Frog Tongue Surface and Hydrophobic Model Membranes. Biochimica et Biophysica Acta, 1289, 322-328.

https://doi.org/10.1016/0304-4165(95)00154-9 